\title{
Regional Recurrences and Hyams Grade in Esthesioneuroblastoma
}

\author{
${ }^{1}$ Department of Otolaryngology-Head and Neck Surgery, University \\ of Toronto, Toronto, Ontario, Canada \\ 2 Department of Medical Imaging, University of Toronto, Toronto, \\ Ontario, Canada \\ ${ }^{3}$ Department of Laboratory Medicine and Pathobiology, University of \\ Toronto, Toronto, Ontario, Canada \\ ${ }^{4}$ Department of Biostatistics, the Princess Margaret Hospital Cancer \\ Centre, Toronto, Ontario, Canada \\ ${ }^{5}$ Department of Radiation Oncology, the Princess Margaret Cancer \\ Centre, Toronto, Ontario, Canada
}

Hedyeh Ziai ${ }^{1} \quad$ Eugene Yu $^{2} \quad$ Ilan Weinreb $^{3} \quad$ Bayardo Perez-Ordonez $^{3} \quad$ Christopher M. K. L. Yao $^{1}$ Wei Xu ${ }^{4}$ Dongyang Yang ${ }^{4}$ lan J. Witterick ${ }^{1}$ Eric Monteiro ${ }^{1}$ Ralph W. Gilbert ${ }^{1}$ Jonathan C. Irish ${ }^{1}$ Patrick J. Gullane ${ }^{1}$ David P. Goldstein ${ }^{1} \quad$ Jolie Ringash $^{5}$ Andrew Bayley ${ }^{5}$ John R. de Almeida ${ }^{1}$

Address for correspondence John R. de Almeida, MD, MSc, Department of Otolaryngology- Head and Neck Surgery, University of Toronto, 200 Elizabeth Street, Suite 8N-881, Toronto, ON, M5G 2C4, Canada (e-mail: john.dealmeida@uhn.ca).

J Neurol Surg B Skull Base 2021;82:608-614.

\begin{abstract}
Keywords

- head and neck

- esthesioneuroblastoma

- Hyams grade

- regional failure

- elective neck treatment

- radiation

- survival

Objective The aim of this study is to determine if Hyams grade may help predict which patients with esthesioneuroblastoma (ENB) tumors are likely to develop regional recurrences, and to determine the impact of tumor extent on regional failure in ENB patients without evidence of nodal disease at presentation.

Design The study was designed as a retrospective review for ENB patients.

Settings The study was prepared at tertiary care academic center for ENB patients. Participants Patients with ENB were included in the study.

Main Outcome Measures Oncologic outcomes (5-year regional and locoregional control (LRC) and overall survival) in patients with Hyams low grade versus high grade. Oncologic outcomes based on radiographic disease extent.

Results A total of 43 patients were included. Total 25 patients (58\%) had Hyams low-grade tumor, and 18 (42\%) had high-grade tumor. Of the 34 patients without regional disease at presentation, 8 (24\%) were treated with elective nodal radiation. There were no statistically significant differences in 5-year regional control in the Hyams low-grade versus high-grade groups (78 vs. $89 \% ; p=0.4$ ). The 5 -year LRC rates in patients with low grade versus high grade were 73 versus $89 \%(p=0.6)$. The 5 -year overall survival rates in patients with lowgrade versus high-grade tumors were 86 versus $63 \%(p=0.1)$. Radiographic extension of disease into the olfactory groove, olfactory nerve, dura, and periorbita were statistically associated with decreased 5-year overall survival (5-year OS 49 vs. $91 \%$ [ $p=0.04]$, 49 vs. $91 \%$ [ $p=0.04], 44$ vs. $92 \%$ [ $p=0.02]$, and 44 vs. $80 \%$ [ $p=0.04]$, respectively).

Conclusion ENBs are associated with a risk of regional failure. The current analysis suggests that Hyams low-grade and high-grade malignancies have comparable rates of early and delayed regional recurrences, although small sample size may limit our conclusions.
\end{abstract}

received

December 11, 2019

accepted

June 2, 2020

published online

October 5, 2020 (c) 2020. Thieme. All rights reserved.

Georg Thieme Verlag KG,

Rüdigerstraße 14,

70469 Stuttgart, Germany
DOI https://doi.org/

10.1055/s-0040-1715809. ISSN 2193-6331. 


\section{Introduction}

Esthesioneuroblastoma (ENB) is a rare malignant neuroendocrine tumor arising from the olfactory epithelium of the nasal cavity and paranasal sinuses. These rare tumors are characterized by a propensity for delayed regional recurrence warranting long-term follow-up. ${ }^{1,2}$ Recurrences in ENB show a biphasic pattern with a propensity for late locoregional recurrences, unlike head and neck squamous cell carcinomas. Several studies have reported regional recurrence rates of up to $40 \%$ in patients presenting without involved nodes at the time of diagnosis. ${ }^{2-9}$

A consensus surrounding nodal management remains elusive given the rarity of this disease. Some authors have suggested elective treatment of the uninvolved neck(s) to prevent regional failure, ${ }^{10,11}$ particularly in patients who are high risk. ${ }^{12,13}$ However, identifying patients who are likely to recur is challenging.

Prognostic factors associated with locoregional control (LRC) included Hyams grade, Dulguerov stage, Kadish stage, extent of resection, and margin status. ${ }^{14-17}$ The Hyams histopathologic grading system is based on cellular architecture and pleomorphism, the presence of neurofibrillary matrix, rosettes, mitoses, necrosis, glands, and calcifications has been shown to have prognostic significance for assessing outcomes. ${ }^{17-19}$ It is often used as a two-tiered grading system, separating tumors into either low grade (grades I and II) or high grade (grades III and IV). ${ }^{15,17-22}$ High-grade ENBs have been associated in some studies with unresectability, leptomeningeal metastasis, frequent lymph node involvement, and poor survival, ${ }^{15,18,19,22-24}$ while other studies have failed to demonstrate an association between Hyams grade and recurrences. ${ }^{14}$ Alternatively, both Kadish and Dulguerov staging systems have been shown to correlate with outcome. $5,14,17,25-27$

The primary aim of this study is to review our institutional patterns of regional recurrence with ENB and to evaluate whether Hyams grade serves as a prognostic factor for the development of neck recurrences in patients with and without elective neck treatment. Furthermore, we explored the prognostic implications of the radiographic extent of disease in this group of patients.

\section{Methods}

\section{Study Population}

Study approval was obtained from the University Health Network Research Ethics Board. Patients with a histopathologic diagnosis of ENB were identified by querying the Princess Margaret Cancer Center Registry, a prospectively maintained database of patients treated at the Princess Margaret Cancer Center and University Health Network between 1972 and 2016. Patient eligibility required: (1) a histologically confirmed diagnosis of ENB, (2) patients treated with curative intent (with surgery and/or radiotherapy, whether with or without chemotherapy), and (3) the availability of pretreatment primary site biopsy or surgical specimen for analysis. Patients were excluded if they had distant metastatic disease and/or noncurative disease at presentation.

\section{Data Collection}

A retrospective review of the medical records, review of pathology by two attending pathologists (I.J.W. and B.P.O.), and imaging review by an attending head and neck radiologist (E.Y.) was performed. Patient demographics, disease, stage, treatment, and oncologic outcomes were collected. Hematoxylin and Eosin stained slides of tumors were retrieved and reviewed, and patients who were not previously classified were classified into Hyams grade based on predefined criteria. ${ }^{17}$ Patients with Hyams grade I and II were then classified as low-grade tumors, and those with grade III and IV tumors were classified as high-grade tumors. Patients were further stratified by Kadish stage. ${ }^{25}$

Imaging (either computed tomography [CT] or magnetic resonance imaging [MRI]) was reviewed by a head and neck radiologist (E.Y.) blinded to tumor histopathology and operative findings. Imaging studies were evaluated for the extent of disease upon pretreatment imaging. The anatomic sites included in our study were: olfactory groove, olfactory nerve, cribriform, dura, periorbita, orbital fat, pterygopalatine fossa, palate, ethmoid sinus, frontal sinus, sphenoid sinus, and nodal involvement. Radiotherapy plans were reviewed to determine treatment to the primary site and the neck(s).

\section{Statistical Analysis}

Statistical analyses were performed using SPSS, version 21.0 SPSS Inc., Chicago, Illinois, United States) and Microsoft Excel. All $p$-values were two-tailed and a value of $p \leq 0.05$ was considered statistically significant. Patient variables were compared using the Fisher's exact test. Our primary outcome measure was regional failure in patients who had no clinically involved nodes at presentation. Crude regional recurrence rates were compared by histopathologic grade (low vs. high). Survival analysis was performed using Kaplan-Meier methods comparing low-grade tumor and high-grade tumors. We performed multivariate analysis using Cox proportional hazards regression methods adjusting for the following covariates: age, sex, Hyams grade, Kadish stage, radiotherapy, chemotherapy, surgical approach, radiographic extent of disease, and margin status.

\section{Results}

\section{Patients}

A total of 43 patients (mean age $=51.5$ years; standard deviation $[S D]=15.1 ; 52 \%$ male) met our inclusion criteria (-Table 1). A total of 25 patients (58\%) had Hyams low-grade tumor, and 18 patients (42\%) had Hyams high-grade tumor. Two patients (5\%) had Kadish stage A, 14 (34\%) had Kadish stage B, 19 (44\%) had Kadish stage C, and 9 (21\%) had Kadish stage D. Follow-up periods ranged from 9 to 315 months (median $=84)$.

\section{Treatment}

Of the 43 patients included in our study, $34(79 \%)$ had no evidence of regional disease at presentation ( - Fig. 1 ). Of these patients with N0 neck at presentation, $8(24 \%)$ had prophylactic neck radiation, and 26 (76\%) did not. Of the eight patients 
Table 1 Patient characteristics

\begin{tabular}{|c|c|c|c|c|}
\hline \multirow[t]{2}{*}{ Variables } & \multicolumn{3}{|c|}{ Number of patients (\%) } & \multirow[b]{2}{*}{$p$-Value } \\
\hline & $\begin{array}{l}\text { Population } \\
n=43\end{array}$ & Hyams low grade $(n=25)$ & Hyams high grade $(n=18)$ & \\
\hline Mean age $( \pm S D)$ & $51.4( \pm 15.2)$ & $50.1( \pm 14.3)$ & $53.2( \pm 16.6)$ & 0.5 \\
\hline Gender, male & $22(51 \%)$ & $14(56 \%)$ & $8(44 \%)$ & 0.5 \\
\hline \multirow[t]{4}{*}{ T category } & T1- 6 (14\%) & T1- $3(12 \%)$ & T1- $3(17 \%)$ & \multirow[t]{4}{*}{0.4} \\
\hline & T2- $13(30 \%)$ & T2- $10(40 \%)$ & T2- 3 (17\%) & \\
\hline & T3- $15(35 \%)$ & T3- $7(28 \%)$ & T3- 8 (44\%) & \\
\hline & T4- 9 (21\%) & T4- $5(20 \%)$ & T4- 4 (22\%) & \\
\hline \multirow[t]{2}{*}{$\mathrm{N}$ category } & N0- 34 (79\%) & N0- 21 (84\%) & N0- 13 (72\%) & \multirow[t]{2}{*}{0.4} \\
\hline & N1- 9 (21\%) & N1- 4 (16\%) & N1- 5 (28\%) & \\
\hline Surgical approach, open & $29(67 \%)$ & $16(64 \%)$ & $13(72 \%)$ & 0.4 \\
\hline Margin status, positive & $4(10 \%)$ & $2(9 \%)$ & $2(12 \%)$ & 1 \\
\hline Radiotherapy (primary and/or neck) & $37(86 \%)$ & $22(88 \%)$ & $15(83 \%)$ & 0.7 \\
\hline Neck radiation & $16(37 \%)$ & $9(36 \%)$ & 7 (39\%) & 1 \\
\hline
\end{tabular}

Abbreviation: SD, standard deviation.

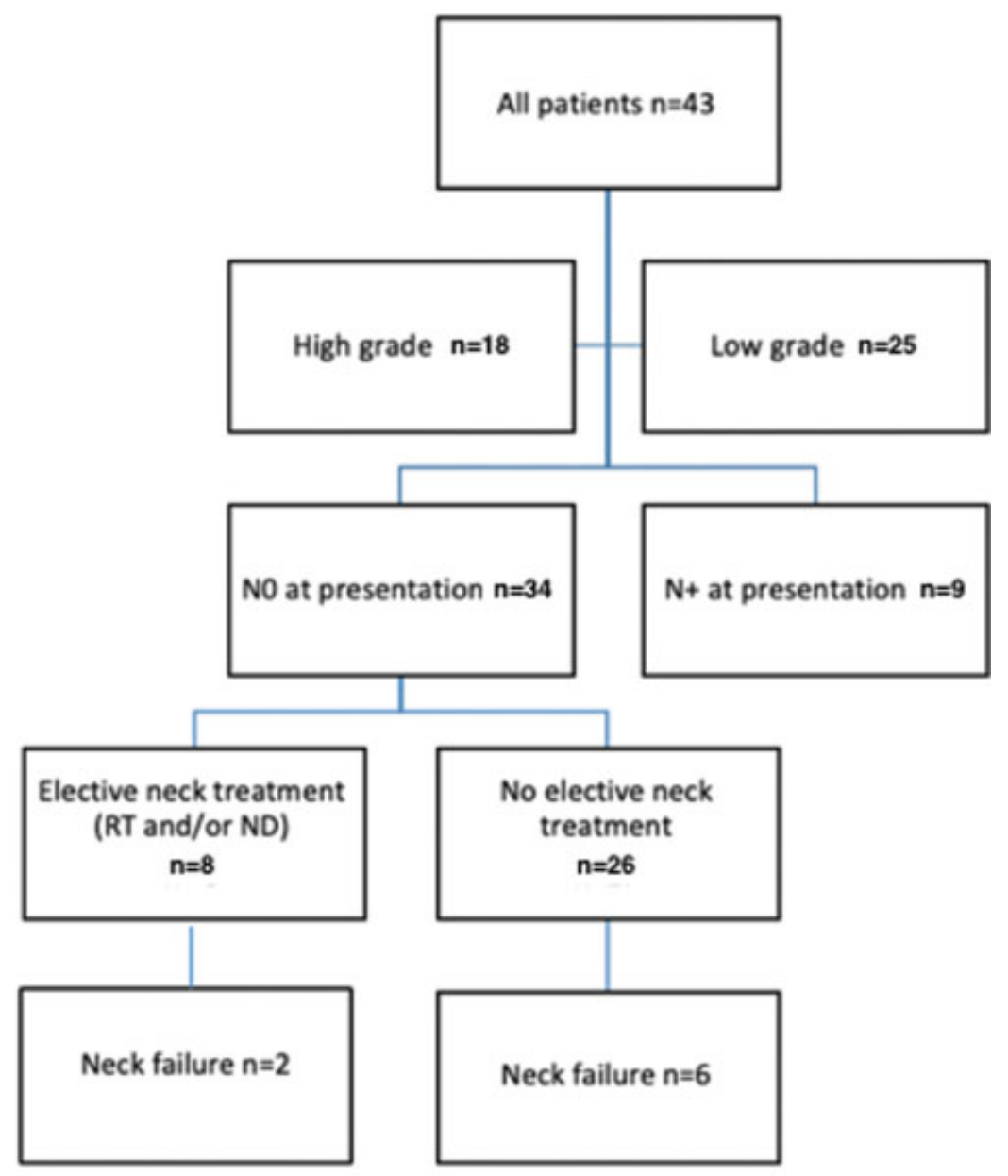

Fig. 1 Patient flow chart. 
with prophylactic neck radiation, six were bilateral and two were ipsilateral. One patient had a prophylactic neck dissection. Of the patients with prophylactic neck radiation, six were Hyams low grade, and two were high grade. All nine patients who had evidence of regional disease at presentation underwent neck dissection, seven of which also had neck irradiation.

A total of 29 patients (67\%) underwent open surgery and 14 (33\%) underwent endoscopic surgery. Total 37 patients received radiation to the primary site, and 16 received radiation to the neck. Four patients received neoadjuvant chemotherapy and none were given adjuvant chemotherapy.

\section{Regional Recurrence and Survival}

A total of $10(23 \%)$ patients developed regional recurrences (median time-to-failure 57 months). Total 6 of 25 patients (24\%) with low-grade tumors and 4 of 18 patients (22\%) with high-grade tumors developed neck recurrences. There were no statistically significant differences in 5-year regional control in the Hyams low-grade tumors and high-grade groups (78 vs. $89 \% ; p=0.4$; - Fig. 2). The 5-year locoregional control rates in patients with low-grade versus high-grade were 73 versus $89 \%$ $(p=0.6)$. The 5 -year overall survival rates in patients with lowgrade versus high-grade tumors were 86 versus $63 \%(p=0.1)$. Univariable and multivariable analysis identified surgical margins and surgical approach as significant predictors of overall survival (surgical margin hazard ratio [HR]: 17.45, $p<0.001$, and endoscopic HR: $1.7 ; p<0.001$ ).

There was no difference in survival between patients that presented with nodal disease versus NO patients on univariate or multivariate analyses for local, regional, or overall survival $(p>0.05)$. Patient with N0 disease at presentation were stratified to determine the impact of prophylactic neck radiation on oncologic control (-Table 2). As shown in - Fig. 3, there was no statistically significant difference in 5-year regional control between those with and without prophylactic neck radiation ( 88 vs. $84 \%, p=0.3$ ). In patients with low grade. tumors, the 5 -year regional control rate in those with and without prophylactic neck radiation was 100 versus $86 \%(p=0.5)$, and 50 versus $90 \%$ in those with high-grade tumors $(p=0.01)$.

\section{Disease Extent: Radiographic Analysis}

A total of 27 patients had imaging available for review (24 MRI scans and 3 CT scans). Of the anatomic sites included in our
Table 2 Impact of prophylactic neck radiotherapy on regional control (N0 patients)

\begin{tabular}{|c|c|c|c|}
\hline & \multicolumn{2}{|l|}{$\begin{array}{l}\text { Population } \\
n=35^{a}\end{array}$} & $p$-Value \\
\hline \multirow[t]{2}{*}{$\begin{array}{l}\text { 5-year } \\
\text { regional } \\
\text { control }\end{array}$} & $\begin{array}{l}\text { Prophylactic } \\
\text { neck RT } \\
n=7\end{array}$ & $\begin{array}{l}\text { No prophylactic } \\
\text { neck RT } \\
n=28\end{array}$ & \multirow[t]{2}{*}{0.3} \\
\hline & $88 \%$ & $84 \%$ & \\
\hline \multicolumn{4}{|c|}{$\begin{array}{l}\text { Hyams low grade } \\
n=21\end{array}$} \\
\hline \multirow[t]{2}{*}{$\begin{array}{l}\text { 5-year } \\
\text { regional } \\
\text { control }\end{array}$} & $\begin{array}{l}\text { Prophylactic } \\
\text { neck RT } \\
n=6\end{array}$ & $\begin{array}{l}\text { No prophylactic } \\
\text { neck RT } \\
n=15\end{array}$ & \multirow[t]{2}{*}{0.5} \\
\hline & $100 \%$ & $86 \%$ & \\
\hline \multicolumn{4}{|c|}{$\begin{array}{l}\text { Hyams high grade } \\
n=13\end{array}$} \\
\hline \multirow[t]{2}{*}{$\begin{array}{l}\text { 5-year } \\
\text { regional } \\
\text { control }\end{array}$} & $\begin{array}{l}\text { Prophylactic } \\
\text { neck RT } \\
n=1\end{array}$ & $\begin{array}{l}\text { No prophylactic } \\
\text { neck RT } \\
n=12\end{array}$ & \multirow[t]{2}{*}{0.01} \\
\hline & $50 \%$ & $90 \%$ & \\
\hline
\end{tabular}

Abbreviation: RT, radiotherapy.

a 1 Hyams grade unknown.

analysis, olfactory groove, olfactory nerve, dura, and periorbital involvement were statistically associated with decreased 5 year overall survival (-Table 3). All other subsite involvements at presentation were not statistically significant for 5-year regional or LRC $(p>0.05)$. As shown in -Table 3 , orbital fat invasion was associated with lower 1-year regional control, suggesting early regional failures ( 33 vs. $91 \%, p=0.03$ ).

\section{Discussion}

In the present study, we observed that in patients with ENB, regional failures are not uncommon with a failure rate of $23 \%$ in the present study consistent with other similar studies in the literature. ${ }^{5,7,8}$ Hyams high-grade tumors had similar regional control rates to patients with low-grade tumors. These findings do not reflect what has been reported in larger series. Goshtasbi et al reported higher regional metastases rates in patients with high-grade tumors (18.2\%) compared with those
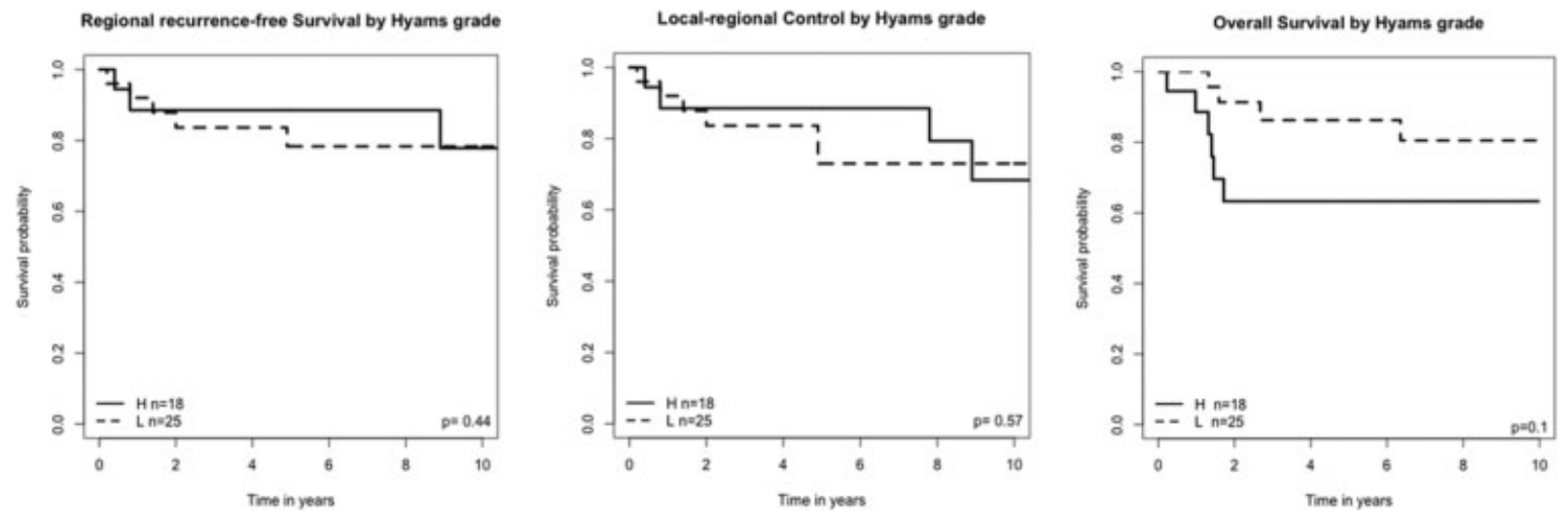

Fig. 2 Kaplan-Meier survival curves for Hyams low grade compared with high grade. 

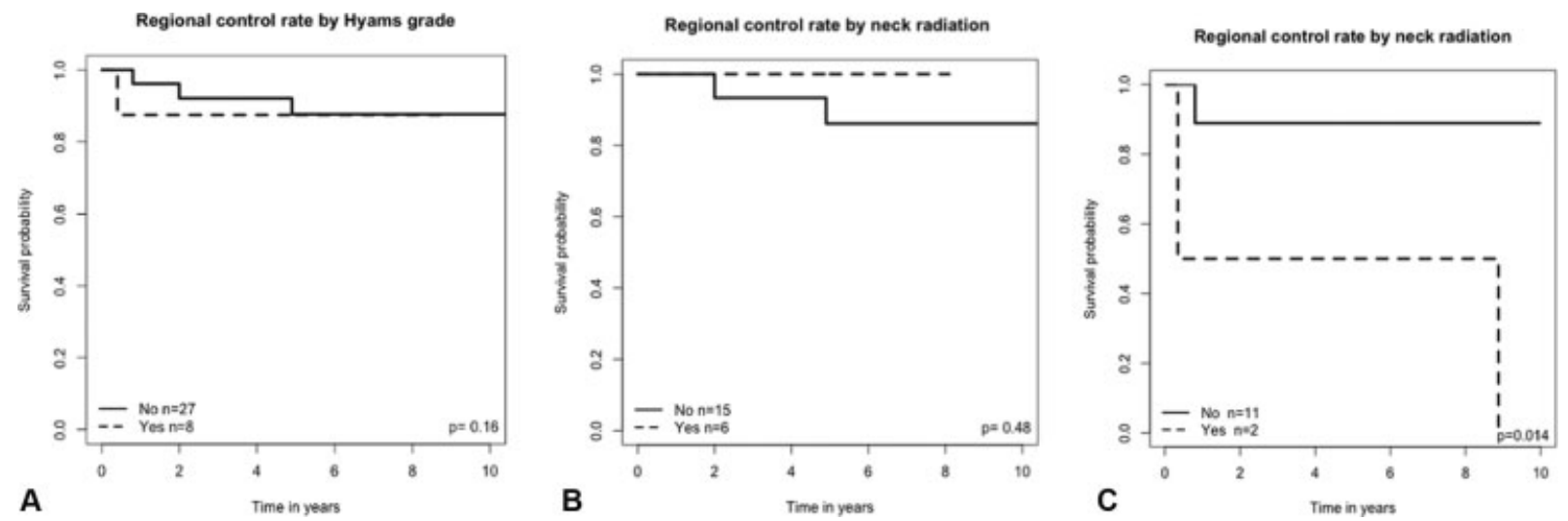

Fig. 3 Kaplan-Meier curves for regional control for patients with and without prophylactic neck radiation (N0 patients). (A) Hyams low and high grade. (B) Hyams low grade. (C) Hyams high grade.

Table 3 Impact of radiographic evidence of site involvement

\begin{tabular}{|l|l|l|l|l|l|l|}
\hline Site & $\begin{array}{l}\text { 5-year locoregional } \\
\text { control }\end{array}$ & $p$-Value & $\begin{array}{l}\text { 5- year regional } \\
\text { control }\end{array}$ & -Value & $\begin{array}{l}5 \text {-year overall } \\
\text { survival }\end{array}$ & $p$-Value \\
\hline Olfactory groove & 63 vs. $83 \%$ & 0.4 & 63 vs. $83 \%$ & 0.4 & 49 vs. $91 \%$ & 0.04 \\
\hline Olfactory nerve & 63 vs. $83 \%$ & 0.4 & 63 vs. $83 \%$ & 0.4 & 49 vs. $91 \%$ & 0.04 \\
\hline Cribriform & 68 vs. $81 \%$ & 0.6 & 68 vs. $81 \%$ & 0.6 & 53 vs. $90 \%$ & 0.08 \\
\hline Dura & 77 vs. $74 \%$ & 0.8 & 77 vs. $74 \%$ & 0.8 & 44 vs. $92 \%$ & 0.02 \\
\hline Periorbita & 62 vs. $80 \%$ & 0.2 & 62 vs. $80 \%$ & 0.2 & 44 vs. $80 \%$ & 0.04 \\
\hline Orbital fat & 33 vs. $91 \%^{\text {a }}$ & 0.03 & 33 vs. $91 \%$ a & 0.03 & 100 vs. $95 \%^{\text {a }}$ & $<0.001$ \\
\hline Pterygopalatine fossa & 50 vs. $88 \%^{\text {a }}$ & 0.3 & 50 vs. $88 \%$ a & 0.3 & 100 vs. $96 \%^{\text {a }}$ & 0.09 \\
\hline Hard palate & 100 vs. $73 \%$ & 0.6 & 100 vs. $73 \%$ & 0.6 & 67 vs. $100 \%$ & 0.5 \\
\hline Ethmoid sinus & 75 vs. $79 \%$ & 0.6 & 75 vs. $79 \%$ & 0.6 & 64 vs. $83 \%$ & 0.5 \\
\hline Frontal sinus & 75 vs. $74 \%$ & 0.8 & 75 vs. $74 \%$ & 0.8 & 67 vs. $69 \%$ & 0.9 \\
\hline Sphenoid sinus & 100 vs. $83 \%$ a & 0.5 & 100 vs. $83 \%$ a & 0.5 & 50 vs. $80 \%$ a & 0.3 \\
\hline Nodal involvement & 57 vs. $80 \%$ & 0.5 & 57 vs. $80 \%$ & 0.5 & 51 vs. $75 \%$ & 0.2 \\
\hline
\end{tabular}

${ }^{\mathrm{a}} 1$-year survival rates as 5-year not applicable.

with low-grade (7.9\%) tumors in a meta-analysis of 525 patients with an odds ratio of 2.08 (95\% confidence interval [CI]: 1.099-3.99, $p=0.03) .{ }^{28}$ Similarly, the authors reported lower 5 -year overall survival rates in high-grade $(54.2 \%)$ versus low-grade tumors (80.2\%). Despite Hyams histopathologic grading system being shown to have prognostic significance in some studies, our study likely fails to demonstrate a difference in regional control.

We did, however, demonstrate that orbital invasion may predispose patients to early regional failures. To the best of our knowledge, this is the first study to demonstrate this finding. While it has been previously shown that orbital invasion is an adverse predictor of outcome ${ }^{29}$ and also that regional failures are associated with poor outcome, the association between orbital invasion and neck metastases has not been shown. The biologic rationale for this is not entirely clear but may have to do with lymphatic drainage of the orbit, which typically drains to either the preauricular lymph nodes or lymph nodes in the upper neck.

Patients without nodal involvement typically have a better prognosis than those presenting with regional nodal involvement. Mortality from disease in patients with lymph node recurrence is significant when compared with those who never develop neck disease. ${ }^{27}$ Among those with regional failures, the overall mortality was 60 versus $32 \%$ for patients without neck recurrence. However, the morbidity of unnecessary overtreatment may also be significant, particularly when the majority of patients are unlikely to develop regional recurrence over the course of their lifetime.

Treatment of the clinically negative neck varies by institution and surgeon with elective neck dissection and radiation playing an important role in many centers. $5,7,30-34$ Elective surgical treatment is associated with well-known morbidity for the patient including wound infection, bleeding, neck and shoulder dysfunction, pain, marginal mandibular nerve injury, and cosmetic deformity. Elective neck radiation similarly can be associated with toxicities such as dry mouth, fibrosis, and lymphedema. Despite the toxicities associated with elective neck treatment, several studies have found conflicting arguments on the need for elective nodal treatment in patients with clinically node negative necks. Many studies suggest a need for elective neck treatment 
based on institutional experiences of regional nodal metastases ranging from 19 to $44 \% .^{5,7,30}$ Elective neck radiation was found to have significant associations with regional control. ${ }^{30-34}$ Conversely, some authors recommend against elective neck treatment. ${ }^{16,35}$ In a review, patients who underwent elective neck radiation or dissection had a rate of subsequent regional metastases up to $75 \%{ }^{10}$ In our cohort, $24 \%$ (8/34 patients) received elective neck treatment (radiation and/or dissection). This was a clinical decision made with variability dependent on the treatment provider. Factors relating to decision to treat elective included the grade of tumor, extent of disease, and factors related to the understanding of disease and regional recurrence patterns which varied over time. Of note, we were more likely to electively treat the neck in more recent years of treatment as aforementioned literature has emerged reporting significant rates of delayed nodal recurrence of ENB patients.

Our study did not corroborate these findings. We found no difference in the development of regional failure from prophylactic neck radiation. Limited sample size may in part explain our inability to identify a difference in regional control in patients who did or did not receive radiation to the neck. We were unable to make comparisons between those who underwent elective neck dissections and those who did not as only three patients in our cohort underwent elective neck dissections, one (33\%) of which had pathological evidence of nodal disease. Determining which patients are likely to develop recurrences is important to help identify those who may benefit from elective neck treatment to prevent the development of regional metastasis and associated morbidity/mortality. Our study failed to demonstrate prognostic factors for failures, although the small sample size limits our conclusions. In the meantime, physicians must balance the risk of recurrence with the added morbidity of radiation therapy and/or surgery to the neck. Furthermore, long-term follow-up is crucial given the high risk of delayed regional failure. The identification of some predictive biomarker for regional failure may help better tailor therapy to those who need it. ${ }^{36,37}$

This study has several limitations. Our relatively small sample size limits the statistical power. The retrospective nature of the study is another limitation. Given the protracted course of regional failures in this disease, some patients may have been lost to follow up or may have sought care for recurrent disease elsewhere and as such not been counted in the analysis. Histopathologic misclassification of ENB is another possibility although in this particular study, pathologic specimens were classified by head and neck pathologist(s).

\section{Conclusion}

ENBs may recur in the neck either in an early or delayed fashion. Patients who recur early either locoregionally or regionally have a poorer prognosis. The present study fails to demonstrate an association between Hyams grade and regional recurrences. However, we did demonstrate the association between olfactory groove, olfactory nerve, dura, and periorbital involvement and poor survival. Future larger scale multicenter collaborative efforts might help confirm or refute potential markers for disease recurrence.

Note

This work was presented at the 29th Annual North American Skull Base Society Meeting in Orlando, Florida, United States, February 15, 2019.

\section{Conflict of Interest}

None declared.

\section{References}

1 Su SY, Bell D, Hanna EY. Esthesioneuroblastoma, neuroendocrine carcinoma, and sinonasal undifferentiated carcinoma: differentiation in diagnosis and treatment. Int Arch Otorhinolaryngol 2014; 18(Suppl 2):S149-S156

2 Peacock JG, Harmsen WS, Link MJ, et al. Risk of delayed lymph node metastasis in clinically N0 esthesioneuroblastoma. J Neurol Surg B Skull Base 2017;78(01):68-74

3 Howell MC, Branstetter BF IV, Snyderman CH. Patterns of regional spread for esthesioneuroblastoma. AJNR Am J Neuroradiol 2011; 32(05):929-933

4 Argiris A, Dutra J, Tseke P, Haines K. Esthesioneuroblastoma: the Northwestern University experience. Laryngoscope 2003;113 (01):155-160

5 Demiroz C, Gutfeld O, Aboziada M, Brown D, Marentette LJ, Eisbruch A. Esthesioneuroblastoma: is there a need for elective neck treatment? Int J Radiat Oncol Biol Phys 2011;81(04): e255-e261

6 Rimmer J, Lund VJ, Beale T, Wei WI, Howard D. Olfactory neuroblastoma: a 35-year experience and suggested follow-up protocol. Laryngoscope 2014;124(07):1542-1549

7 Beitler JJ, Fass DE, Brenner HA, et al. Esthesioneuroblastoma: is there a role for elective neck treatment? Head Neck 1991;13(04): 321-326

8 Gore MR, Zanation AM. Salvage treatment of late neck metastasis in esthesioneuroblastoma: a meta-analysis. Arch Otolaryngol Head Neck Surg 2009;135(10):1030-1034

9 Simon JH, Zhen W, McCulloch TM, et al. Esthesioneuroblastoma: the University of Iowa experience 1978-1998. Laryngoscope 2001;111(03):488-493

10 Zanation AM, Ferlito A, Rinaldo A, et al. When, how and why to treat the neck in patients with esthesioneuroblastoma: a review. Eur Arch Otorhinolaryngol 2010;267(11):1667-1671

11 Resto VA, Eisele DW, Forastiere A, Zahurak M, Lee DJ, Westra WH. Esthesioneuroblastoma: the Johns Hopkins experience. Head Neck 2000;22(06):550-558

12 Martel J, Darrouzet V, Duclos JY, Bébéar JP, Stoll D. [Olfactory esthesioneuromas]. Rev Laryngol Otol Rhinol (Bord) 2000;121 (04):227-236

13 Kaur G, Kane AJ, Sughrue ME, et al. The prognostic implications of Hyam's subtype for patients with Kadish stage C esthesioneuroblastoma. J Clin Neurosci 2013;20(02):281-286

14 Bachar G, Goldstein DP, Shah M, et al. Esthesioneuroblastoma: The Princess Margaret Hospital experience. Head Neck 2008;30(12): 1607-1614

15 Malouf GG, Casiraghi O, Deutsch E, Guigay J, Temam S, Bourhis J. Low- and high-grade esthesioneuroblastomas display a distinct natural history and outcome. Eur J Cancer 2013;49(06):1324-1334

16 Ozsahin M, Gruber G, Olszyk O, et al. Outcome and prognostic factors in olfactory neuroblastoma: a rare cancer network study. Int J Radiat Oncol Biol Phys 2010;78(04):992-997

17 Hyams VJ. Olfactory neuroblastoma (Case 6). In: Batsakis JG, Hyams VJ, Morales AR, eds. Special Tumors of the Head and Neck. Chicago: ASCP Press; 1982:24-29 
18 Kane AJ, Sughrue ME, Rutkowski MJ, et al. Posttreatment prognosis of patients with esthesioneuroblastoma. J Neurosurg 2010; 113(02):340-351

19 Van Gompel JJ, Giannini C, Olsen KD, et al. Long-term outcome of esthesioneuroblastoma: hyams grade predicts patient survival. J Neurol Surg B Skull Base 2012;73(05):331-336

20 Dias FL, Sa GM, Lima RA, et al. Patterns of failure and outcome in esthesioneuroblastoma. Arch Otolaryngol Head Neck Surg 2003; 129(11):1186-1192

21 Gallagher KK, Spector ME, Pepper JP, McKean EL, Marentette LJ, McHugh JB. Esthesioneuroblastoma: updating histologic grading as it relates to prognosis. Ann Otol Rhinol Laryngol 2014;123(05): 353-358

22 Morita A, Ebersold MJ, Olsen KD, Foote RL, Lewis JE, Quast LM. Esthesioneuroblastoma: prognosis and management. Neurosurgery 1993;32(05):706-714, discussion 714-715

23 Fukushima S, Sugita Y, Niino D, Mihashi H, Ohshima K. Clincopathological analysis of olfactory neuroblastoma. Brain Tumor Pathol 2012;29(04):207-215

24 Bell D, Saade R, Roberts D, et al. Prognostic utility of Hyams histological grading and Kadish-Morita staging systems for esthesioneuroblastoma outcomes. Head Neck Pathol 2015;9(01): 51-59

25 Kadish S, Goodman M, Wang CC. Olfactory neuroblastoma. A clinical analysis of 17 cases. Cancer 1976;37(03):1571-1576

26 Dulguerov P, Calcaterra T. Esthesioneuroblastoma: the UCLA experience 1970-1990. Laryngoscope 1992;102(08):843-849

27 Naples JG, Spiro J, Tessema B, Kuwada C, Kuo CL, Brown SM. Neck recurrence and mortality in esthesioneuroblastoma: Implications for management of the N0 neck. Laryngoscope 2016;126(06): 1373-1379
28 Goshtasbi K, Abiri A, Abouzari M, et al. Hyams grading as a predictor of metastasis and overall survival in esthesioneuroblastoma: a meta-analysis. Int Forum Allergy Rhinol 2019;9(09): 1054-1062

29 Li R, Tian S, Zhu Y, et al. Management of orbital invasion in esthesioneuroblastoma: 14 years' experience. Radiat Oncol 2019; 14(01):107

30 Monroe AT, Hinerman RW, Amdur RJ, Morris CG, Mendenhall WM. Radiation therapy for esthesioneuroblastoma: rationale for elective neck irradiation. Head Neck 2003;25(07):529-534

31 Hollen TR, Morris CG, Kirwan JM, et al. Esthesioneuroblastoma of the nasal cavity. Am J Clin Oncol 2015;38(03):311-314

32 Koka VN, Julieron M, Bourhis J, et al. Aesthesioneuroblastoma. J Laryngol Otol 1998;112(07):628-633

33 Yin ZZ, Luo JW, Gao L, et al. Spread patterns of lymph nodes and the value of elective neck irradiation for esthesioneuroblastoma. Radiother Oncol 2015;117(02):328-332

34 Modesto A, Blanchard P, Tao YG, et al. Multimodal treatment and long-term outcome of patients with esthesioneuroblastoma. Oral Oncol 2013;49(08):830-834

35 Noh OK, Lee SW, Yoon SM, et al. Radiotherapy for esthesioneuroblastoma: is elective nodal irradiation warranted in the multimodality treatment approach? Int J Radiat Oncol Biol Phys 2011; 79(02):443-449

$36 \mathrm{Kim}$ JW, Kong IG, Lee $\mathrm{CH}$, et al. Expression of $\mathrm{Bcl}-2$ in olfactory neuroblastoma and its association with chemotherapy and survival. Otolaryngol Head Neck Surg 2008;139(05):708-712

37 Oberländer M, Alkemade H, Bünger S, et al. A 'waterfall' transferbased workflow for improved quality of tissue microarray construction and processing in breast cancer research. Pathol Oncol Res 2014;20(03):719-726 